\title{
Phenylketonuria (PKU) - A Success Story
}

\author{
William B. Hanley \\ The Hospital for Sick Children $\mathcal{E}$ The University of Toronto, Department of Paediatrics, \\ Canada
}

\section{Introduction}

Phenylketonuria (PKU; OMIN 261600 and 261630) is an autosomal recessive geneticmetabolic disease. It is one of the most common of over 200 known such diseases, at least 30 of which have treatments to ameliorate the adverse effects. PKU is one of the first diseases causing mental and physical disability for which successful treatment has been developed. The cause of PKU is defective function of the enzyme phenylanine hydroxylase (EC 1.14.16.1) which converts phenylalanine to tyrosine. A cofactor is tetrahydrobiopterin (BH4). The subsequent elevation of phenylalanine in the blood and brain results in profound, irreversible, mental retardation in a large number of the affected individuals. The fetuses of nubile women with PKU are at risk as a result of the toxic effect on organ development of high phenylalanine levels during pregnancy (Levy \& Ghavama, 1996).

\section{History}

The discovery of PKU was by Asbjorn Folling (Folling, 1934) a Norwegian physician/biochemist who noted that the addition of ferric chloride to the urine of 2 retarded sibs produced a transient green coloration. He then demonstrated that this was caused by the phenylketone, phenylpyruvic acid, a side product of the transammination of phenylalanine which occurs when phenylalanine blood levels are $>600 \mu \mathrm{mol} / \mathrm{L}$ (normal values $80-100 \mu \mathrm{mol} / \mathrm{L}$ ). He went on to test a number of retarded patients in a local institution and found 10 with "imbicilitas phenylpyruvica". Several researchers in Europe and North America then visited large institutions for the mentally retarded searching for individuals with PKU. One of whom, George Jervis (Jervis, 1937), examined 8043 "inmates" of 3 institutions in New York State and found 50 with PKU - most were profoundly retarded. Eventually it was estimated that $1-3 \%$ of mentally handicapped individuals had PKU. Penrose (Penrose, 1937) demonstrated the autosomal recessive nature and renamed it "phenylketonuria". In 1953 it was shown that the enzyme phenylalanine hydroxylase was deficient (Jervis, 1953). Successful dietary treatment with a restricted phenylalanine diet was reported in 1954 (Bickle et al, 1954). It became evident that much if the irreversible damage occurred in the first few weeks/months of life and early diagnosis was crucial. This led to the advent of mass newborn PKU screening (Guthrie \& Susi, 1963). The majority of the developed world now screens newborn infants for PKU within the first few days of life. In 1983 the cDNA for the phenylalanine hydroxylase gene was cloned and mapped to chromosome 12 (12q22-q24.1) (Woo et al, 1983). To date more than 500 alleles have been discovered. 


\section{The biochemistry of PKU}

Phenylalanine is normally converted to tyrosine by the enzyme phenylalanine hydroxylase. This process is catalyzed by the cofactors tetrahydrobiopterin (BH4), $\mathrm{O} 2$ and iron (Figure 1). $\mathrm{BH} 4$ reduces NADP to NADPH. After oxidation to dihydropterin, NADPH regenerates $\mathrm{BH} 4$. In the absence of phenylalanine hydroxylase phenylalanine metabolism is diverted into a minor pathway that is not employed normally. The alanine portion of the molecule is transaminated to pyruvate, generating phenylpyruvate. This phenylketone spills into the urine; hence the name phenylketonuria (PKU). The genetics of $\mathrm{BH} 4$ is complicated: several genetically determined enzymes are involved - including dihydropteridine reductase (the most common to be affected), guanosine triphosphate cyclohydrolase I, 6-pyruvoy-1tetrahydrobiopterin synthetase, sepiapterin reductase and tetrohydropterin 2'-keto reductase (Matalon et al, 1989). Reduced or absent function of phenylalanine hydroxylase results in PKU and malfunction of the $\mathrm{BH} 4$ enzymes produces the biopterin deficiency variants. Tyrosine becomes an essential amino acid and because of the block in conversion of phenylalanine to tyrosine patients with PKU have low tyrosine levels (Hanley et al, 2000). Hence tyrosine supplementation to dietary therapy is often carried out.

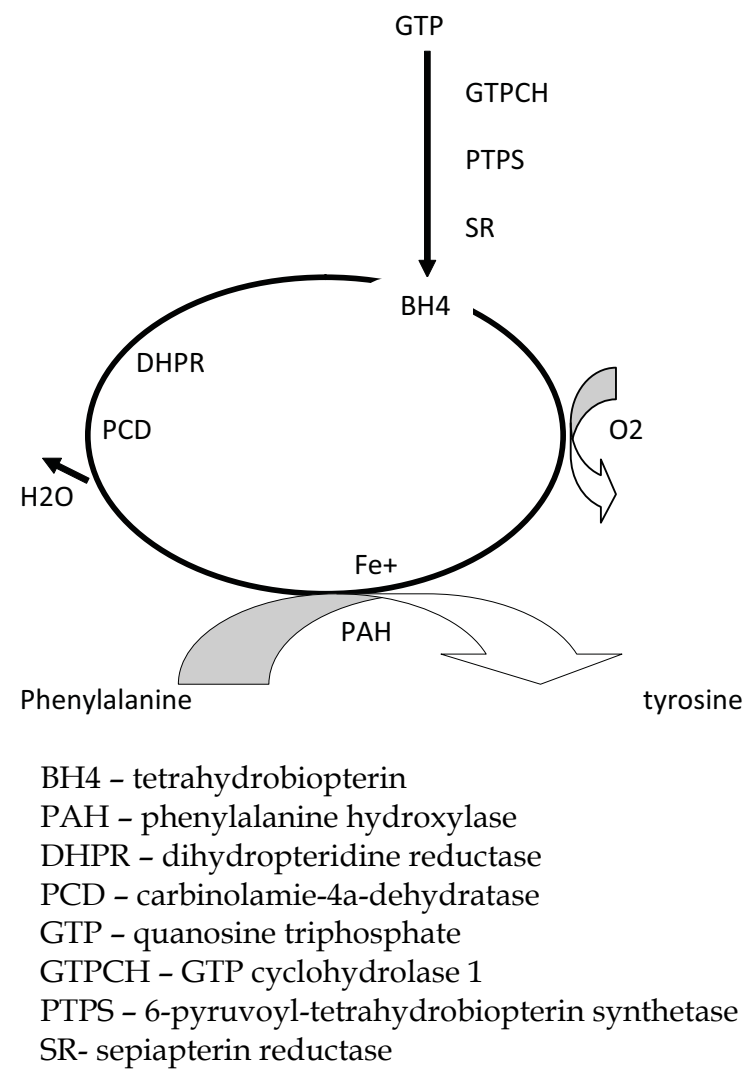

Fig. 1. The Biochemistry of the hydroxylation of phenylalanine to tyrosine 


\section{The clinical phenotypes of PKU}

When universal newborn screening began in the 1960-70's it was found that milder forms of phenylketonuria existed. Before newborn screening most of the individuals recognized as having PKU were those with Classical PKU (blood phenylalanine levels on an unrestricted diet $>1200 \mu \mathrm{mol} / \mathrm{L}$ ). Unfortunately, there is no uniform, world-wide, agreed upon classification of the PKU phenotypes. There are probably a couple of dozen in the literature. This makes it difficult for the uninitiated. The most widely used (Guttler, 1980) is shown in Table 1.

Phenotype

Classical PKU

Mild/Atypical PKU

Non-PKU mild

hyperphenylalaninemia (MHP)

Biopterin deficiency PKU
Blood phenylalanine (unrestricted diet) - $\mu \mathrm{mol} / \mathrm{L}$

$>1200$

$600-1200$

200-600

variable

Table 1. A classification of the PKU phenotypes

\subsection{Classical PKU}

The Classical PKU phenotype (blood phenylalanine levels $>1200 \mu \mathrm{mol} / \mathrm{L}$ on unrestricted diet) usually makes up just over $50 \%$ of all cases and is responsible for the great majority of those profoundly retarded when untreated or late treated. This percentage varies, however, by jurisdiction, race and country.

\subsection{Atypical/Mild PKU}

Atypical/Mild PKU (phenylalanine levels $600-1200 \mu \mathrm{mol} / \mathrm{L}$ on unrestricted diet) appears to constitute about $20-25 \%$ of all cases. These patients suffer less severe, as a rule, intellectual damage if untreated. Treatment is somewhat easier since more natural protein is able to be administered and phenylalanine blood levels do not spike as high under metabolic stress.

\subsection{Non-PKU mild hyperphenylalaninemia (MHP)}

This phenotype makes up about $25-30 \%$ of all cases. Despite phenylalanine levels of 200-600 $\mu \mathrm{mol} / \mathrm{L}$ (two to six times the normal range) this variant has, in several studies, shown to be benign (Smith et al, 2000; Weglage et al, 2001). However, this premise has recently come under question (van Spronsen, 2011). The prevalence in Taiwan is 52\% (Niu et al, 2010), double that of most jurisdictions.

\subsection{Biopterin deficiency PKU}

This variant is caused by deficient function of one of several enzymes facilitating the biosynthesis or regeneration of the cofactor tetrahydrobiopterin (BH4) (Matalon et al, 1989). Phenylalanine blood levels can vary from slightly elevated to very high. It accounts for 1-3\% of all cases of PKU, although it may be higher in Asians - 16\% in Taiwan (Niu et al, 2010). Since $\mathrm{BH} 4$ is also a cofactor in the metabolism of the amino-acids tyrosine and tryptophan, it's deficiency is devastating to the infant brain (it was originally labeled as "malignant 
PKU"). The treatment is more complicated and involves the administration, not only of BH4, but also L-dopa, 5-hydroxytryptophan, carbidopa and folinic acid (Matalon et al, 1989). The majority of newborn screening programs have a protocol to detect biopterin deficiency in all samples testing positive for elevated phenylalanine including BH4 loading, analyzing blood or urinary pterins and determining blood dihydropteridine reductase activity (Blau et al, 2005).

\section{Genotypes of phenylalanine hydroxylase deficiency}

Over 500 alleles have been described (Scriver, 2007). In general two severe mutations result in severe (Classical PKU) disease, while the presence of just one mild mutation usually signals mild disease. However, many exceptions arise such that the co-relation between phenotype and genotype is sometimes unpredictable. This has raised the question of modifier genes entering the equation. The majority of the defects are missense mutations but splice-site, nonsense and silent mutations as well as frame shifts, larger deletions and insertions may occur (Scriver, 2007). The phenylketonuria genotype database can be accessed on the internet @ www.pahdb.mcgill.ca.

\section{The worldwide prevalence of PKU and its variants}

PKU occurs worldwide but is most frequent in European Caucasians and their descendants - where the prevalence is about 1:10,000 births (Loeber, 2007). There is wide variation, however, from country to country - even in Europe. The frequency in Ireland, for example, is 1:4,500 (Loeber, 2007) while that in Finland is 1:100,000 to 1:200,000 (Autti-Ramo et al, 2005). The severe (Classical) forms occur more often in Northern and Eastern Europe (e.g. $70 \%$ have Classical PKU in Poland (Zekanowski et al, 1997) with increasing numbers of the milder variants in Southern Europe (e.g. higher incidence of the milder variants in Spain (Desviat et al, 1999). The North American prevalence is about 1:15,000 (NIH, 2000). There is evidence of very high occurrence in some Middle Eastern Muslim countries related to consanguinity (Goldbar et al, 2002). In Israel the overall incidence is 1:11,000 with Ashkenazi Jews having only non-PKU mild hyperphenylalaninemia (Szeinberg et al, 1969). In Japan the incidence is 1:108,000 (Tada et al, 1984). It is unclear as yet what the frequency is in China and Taiwan. Early reports suggested an incidence of only 1:212,000 (Pangkanon et al, 2003), but more recently Nui (Nui et al, 2010) report an incidence of 1:19,412 in Taiwan. Similar figures have been reported from China with current estimates at 1:15,000 (Zhan et al, 2009). The frequency is apparently low in Blacks and Aboriginals but no extensive data are available.

\section{Maternal PKU (MPKU)}

Maternal PKU embryopathy includes microcephaly, mental retardation, congenital heart disease, intrauterine growth retardation, facial dysmorphism and mid-brain defects (Levy \& Ghavami, 1996). The clinical features are identical to those of the foetal alcohol syndrome (Clarren \& Smith, 1978; Autti-Ramo et al, 1992) and, in fact, may be due to the same mechanism - interference with the activity of pyruvate dehydrogenase (Robinson, 1987; Hard, 2001). Numerous reviews have been published (Hanley et al, 1987) since the problem of MPKU was initially raised in 1963 by Mabry (Mabry et al, 1963). The most comprehensive 
study was that of Lenke (Lenke \& Levy, 1980) with a world -wide review of 524 pregnancies in 155 women with untreated PKU. Their findings revealed, in 172 offspring of mothers with Classical PKU, 92\% with mental retardation, 73\% with microcephaly, $12 \%$ with congenital heart disease and $40 \%$ with intrauterine growth retardation. Of the 120 born of mothers with the milder variants of PKU the foetal complications were significantly fewer. These data prompted the initiation of several prospective studies, one of which was the International (USA, Canada, Germany) Maternal PKU Collaborative Study (Koch et al, 2003), which ran from 1984 to 2002 and enrolled 382 women with PKU who completed 572 pregnancies. The outcomes demonstrated, unequivocally, the importance of good dietary control prior to conception or early in pregnancy (8-10 weeks) and the devastating effects of late initiation or poor control of diet therapy in the great majority of offspring.

\subsection{The problem of undiagnosed or lost to follow-Up females with PKU}

There is a, little recognized, problem of women with PKU, unknowingly at risk for producing offspring with maternal phenylketonuria embryopathy. These women were born in jurisdictions where screening neonates for PKU was not yet initiated or who are lost to follow-up by their treatment clinics. This is compounded by the little known significant incidence of normal IQ in untreated PKU individuals. A recent review of the world literature from 1990 to 2007 (Hanley, 2008) uncovered reports of 60 women with previously undiagnosed PKU, most with relatively normal intellectual function, who had produced 119 offspring, all profoundly damaged. A plea was made for selective screening of pregnant women for PKU. A further case of maternal PKU recently diagnosed in a 33 year old woman in Greece only after the birth of a damaged foetus has been reported (Bouchlariotou et al, 2009) emphasizing that undiagnosed maternal phenylketonuria remains a problem.

\section{Universal neonatal screening for PKU}

When it became obvious that early diagnosis (in the first few weeks of life) was crucial to successful treatment of PKU the idea of neonatal screening was introduced. It began with ferric chloride testing of wet diapers but numerous false negative results were discovered. The reason for this soon became obvious. The immature kidney of the young infant with PKU does not excrete phenylpyruvic acid until about 6 weeks of age. Furthermore phenylpyruvic acid is not produced until the blood phenylalanine level is $>600 \mu \mathrm{mol} / \mathrm{L}$. This led to a focus on blood testing. Robert Guthrie (Guthrie \& Susi, 1963), whose son was mentally retarded and whose niece was discovered to have PKU at age 18 months, developed the bacterial inhibition assay method of PKU screening. Subsequently universal, mass newborn screening for PKU spread to encompass many jurisdictions around the world. This spread has been very gradual and erratic. In many countries health care is the responsibility of individual states/provinces within the country. Generally, universal newborn PKU screening began in USA, Canada, Austrailia \& New Zealand between 1963 and 1967. In USA PKU Guthrie screening began in Oregon and Massachusetts in 1963, but not until 1985 in Mississippi. In Canada it began in 1965 in Nova Scotia and Ontario but not until 1975 in Newfoundland. In Europe PKU neonatal screening began, for the most part, between 1964 and 1974 but later, for example, in Poland (1976), Spain (1980-85), France (1964-78), NE Italy (1978), Sicily (1990), Estonia (1993), The Netherlands (1974), Czech 
Republic (1975) (Hanley, 2008), Slovakia (1972) (Knapkova \& Dluholucky, 2011), Ukraine (1985) (Grechanina et al, 2011). Finland does not screen neonates for PKU (incidence 1100,000 to 1:,200,000 - one new case every 2-4 years) (Autti-Ramo, et al, 2005). Some other countries do not yet screen their neonates for PKU and in others it is incomplete. In the Middle East, for example, Kazakhstan began PKU screening in 2006 (Salimbaeva et al, 2011) and Qartar in 2003 (Ghsssan, 2011). China (PKU incidence 1:17,000 to 1:33,000) (Jiang, 2003; Zao et al, 2005), began screening in 1992-1997 in Beijing, Shanghai and eight other cities but as of 1999 only $1.2 \%$ of neonates were screened (Gu \& Chen, 1999).

\section{The treatment of PKU}

In 1954 Bickle (Bickle et al, 1953) and associates were the first to introduce treatment for PKU with a phenylalanine restricted diet. The first efforts were very crude and the initial patient was an older child already damaged. The improvement in behavior prompted more refined efforts. It became obvious that very early diagnosis was crucial as much of the adverse effect on the brain in the first few months of life were irreversible, hence the initiation of universal newborn screening (Guthrie \& Susi, 1963).

\subsection{Restricted phenylalanine diet therapy}

The mainstay, for the past 50 years, of treatment is skillful diet manipulation by a metabolic dietician/nutritionist. The goal is to lower the blood/brain phenylalanine levels to "safe" values while still providing sufficient phenylalanine for protein formation and growth and to prevent catabolism. The diet is semi-synthetic, restrictive, expensive and not very palatable. It includes three components: 1. "Medical Food" (formula) - a synthetic phenylalanine-free drink containing all the other essential amino-acids plus minerals, vitamins, iron and other key trace elements. 2. Natural foods - strictly "veganvegetarian" (no higher protein foods such as milk, meat, fish, chicken, bread, eggs, cheese, nuts, certain legumes). This component of the diet provides just enough phenylalanine to prevent catabolism and promote growth. 3. Specially designed (expensive) low protein foods to give needed variety and calories to the diet. The cost of this diet is $\$ 20,000$ to $\$ 40,000$ (US) yearly. This cost is usually covered by government health plans or private insurance companies. One of the problems, lack of palatability, may be eased by the inclusion of a new modality, glycomacropeptide, in the medical food (Ney et al, 2009). This product is a natural protein derived from goat milk during cheese making. It is low in phenylalanine and high in most long chain amino acids, although tyrosine and tryptophan must be added.

Target levels for blood phenylalanine are 120-360 $\mu \mathrm{mol} / \mathrm{L}$ (Waisbren et al, 2007) and 120-240 $\mu \mathrm{mol} / \mathrm{L}$ for pregnancy (normal range 80-100). Recommended levels are arbitrary and variable but less stringent after the age of 12 years. Unfortunately there is no consistency in these recommendations for adolescents and adults which vary widely (Table 2) (Hanley, 2008). Since there is no "acute metabolic/ neurological crisis" if blood levels rise (in contrast to some other inherited metabolic diseases) it is very common for diets to be less well controlled as the patients get older. In Europe and North America up to 50\% of adult PKU patients are lost to follow-up. Of the remainder, 30-90\% are "off diet". Of those on diet, 70\% are not in good control (Hanley, 2004a). 


$$
\begin{aligned}
& \mu \mathrm{mol} / \mathrm{L} \\
\text { Children age 0-12 years } & -120-360 \\
\text { Adolescents and adults } & - \text { USA }<900 \\
& - \text { UK }<700 \\
& - \text { Germany }<240 \text { "till age 10 } \\
& <900 \text { age 10-15 } \\
& <1200 \text { after age 15 } \\
& \text { - France } \quad<1200 \text { after age 15 }
\end{aligned}
$$

Table 2. Recommended Guidelines for phenylalanine values in treated PKU

The great majority of patients with PKU who were treated from early infancy, have IQ's within the normal range (90-110) but are 5-15 points below their unaffected sibs and parents (Koch et al, 1984). In addition they often have neuropsychological (frontal lobe function) deficits (Welsh et al, 1990) and/or emotional/psychological/psychiatric problems (Gentile et al, 2010; Brumm et al, 2010). The causes of these "suboptimal" outcomes are multifactorial, but this has led to exploration of new, additional or alternative treatment modalities.

\subsubsection{Nutritional complications of dietary therapy}

Since diet therapy for PKU involves a semi-synthetic diet which may not be as bio available as natural foods, a number of nutritional deficiencies have emerged. Many have been dealt with. Vitamin B12 deficiency, for example, was found in a number of adolescents and young adults who were poorly compliant (Hanley et al, 1996; Robinson et al, 2000). Low bone density has been documented in up to $1 / 3$ (Modan-Moses et al, 2007) of treated PKU patients. Long-chain fatty acid (arachidonic acid and docosahexaenoic acid (present only in foods from animal sources) have an important role in neurotransmission and vision. Yi (Yi et al, 2011) found a relationship between RBC docosahexaeonic acid and verbal ability.

\subsubsection{Portable PKU monitoring device (Biomarin Inc)}

Control of blood phenylalanine levels, especially in infants and toddlers, is critical to long term prevention of neurotoxic effects on the brain. The usual process is for the family to take heel-prick Guthrie blood spots on a regular basis and mail them in to the treatment centres. This involves a time span of 4-7 days to obtain results. By this time an episode that caused a variation in the blood levels may be over. The ideal situation would be for a home monitoring device to provide instant data (similar to the "Glucometer" for diabetics). Samples could be taken as often as daily. Regular phone consultation with the dietician/nutritionist would ensue. Biomarin Inc technicians are actively working on a prototype to move on to clinical trials.

\subsection{Pharmacological treatment}

\subsubsection{Tetrahydrobiopterin (BH4, Sapropterin dihydrochloride, Kuvan®)}

The report, in 1999 (Kure et al, 1999), of several patients with phenylalanine hydroxylase deficiency PKU who responded to administration of $\mathrm{BH} 4$ with a decrease in blood 
phenylalanine led to a virtual explosion of research and publications over the next 10 years. It appears that some individuals with PKU may have residual phenylalanine hydroxylase enzyme activity and, in this group, BH4 can act as a chemical chaperone to enhance its activity. Sapropterin dihydrochloride - Kuvan ${ }^{\circledR}$, Biomarin Pharmaceutical Inc., CA, USA (USA \& Canada), Merk Serona SA, Geneva, Switzerland (the rest of the world) plus Biopten ${ }^{\circledR}$, Japan - Asubio Pharm Co Ltd (Tokyo, Japan), is a synthetic dihydrochloride salt form of the biologically active 6R-diasteroisomer of $\mathrm{BH} 4$ (5,6,7,8- tetrahydrobiopterin). Orphan drug designation and regulatory approval has been obtained in many jurisdictions. It comes as a soluble $100 \mathrm{mg}$ oral tablet. BH4 is also a cofactor for tyrosine hydroxylase, tryptophan hydroxylase, glycerine ether mono-oxydase and nitric oxide synthetase. Thus it is involved in the synthesis of various neurotransmitters including adrenaline, noradrenaline, dopamine, serotonin and nitrous oxide (Blau et al, 2005). "Response" to BH4 is, arbitrarily, set at a blood phenylalanine drop of $>30 \%$ and the usual dose is $10-20$ $\mathrm{mg} / \mathrm{Kg} /$ day - with $20 \mathrm{mg}$ usually favored.

Numerous clinical trials have been carried out and more are ongoing. These include i) "PKU-001" (Burton et al, 2007) where 490 adolescent and adult patients (mean age 20 years) with "poorly controlled" PKU were studied. An 8 day course of BH4 (10 mg/Kg/day) was given: Ten percent of subjects with Classical PKU responded, $24 \%$ of those with Mild/Atypical PKU responded and 54\% with MHP responded. ii) PKU-003 (Levy et al, 2007) examined the BH4 $(10 \mathrm{mg} / \mathrm{kg} /$ day) response in 89 patients previously identified as "responders" in the PKU-001 trial. This was a multicentre, randomized, double-blind, placebo-controlled 6 week trial. Only $44 \%$ of the study subjects responded, but they showed a statistically significant $(\mathrm{p}<0.001)$, persistent, response. iii) In a further phase III study (PKU-004) Lee (Lee et al, 2008) enrolled 80 patients (age $>8$ years) in a 22-week study administering $\mathrm{BH} 4$ doses of $5,10 \& 20 \mathrm{mg} / \mathrm{Kg} /$ day, showing consistent response, favoring the $20 \mathrm{mg} / \mathrm{Kg}$ dose. iv) A study, in children age 4-12 years (PKU-006), to evaluate the ability of BH4 supplementation to increase the phenylalanine tolerance has been reported. This was a randomized, placebo controlled trial (Trefz et al, 2009). Ninety 4-12 year old children with well controlled PKU were studied. They were challenged with $20 \mathrm{mg} \mathrm{BH} 4 / \mathrm{Kg} /$ day for 8 days. Forty-six (51\%) responded with a drop in blood phenylalanine of $>30 \%$. They showed a significant $(\mathrm{p}<0.001)$ increase tolerance for dietary phenylalanine. This enabled the addition of more "natural" (? bio available) protein in the diet. More recent abstracts have claimed a higher incidence of BH4 "responders" using higher doses $(20 \mathrm{mg} / \mathrm{Kg} /$ day $)$ for longer periods (up to 1 month). For example Hennerman (Hennerman et al, 2005) reports, when giving a BH4 load of $20 \mathrm{mg} / \mathrm{Kg}$ to 40 neonates with a positive PKU screen, 18 (45\%) responded. Five of these had Classical PKU and had sustained response to $\mathrm{BH} 4$. Phenylalanine tolerance increased from $18-19 \mathrm{mg} / \mathrm{kg}$ to $30-80 \mathrm{mg} / \mathrm{kg}$ "allowing substantial easing of dietary restrictions". Further studies are ongoing regarding long term safety and efficacy. One, in Europe, the KAMPER study (Champigneulle et al, 2009) will carry out regular evaluations of 625 patients in 100 European centres. Another, in USA (Kurczynski et al 2009), will follow 3500 patients for up to 15 years.

Because of BH4's multiple co-factor activity it has been postulated that it might be effective in treating some of the psychological/psychiatric aspects in adults. .Mosley (Mosley et al, 2010) reports twelve, older, never treated PKU adults with "measureable maladaptive behavior", treated with $20 \mathrm{mg} / \mathrm{Kg} /$ day of BH4. They found no change in blood 
phenylalanine, an increase in blood tyrosine and "significant" improvement in behavior. Koch (Koch et al, 2002a) reports significant improvement of depression and panic attacks in a patient with mild PKU with a BH4 maintenance dose of only $100 \mathrm{mg} /$ day.

$\mathrm{BH} 4$, therefore, is an addition to the armamentarium of treatment options, although those patients needing it the most, Classical PKU, benefit the least. Patients with Atypical/Mild PKU would benefit the most (50-60\% responders), some of whom can be managed without phenylalanine dietary restrictions. Up to $90 \%$ of subjects with Non-PKU mild hyperphenylalaninemia respond to $\mathrm{BH} 4$ but there is not yet good evidence to justify treatment in this group (Hanley, WB, 2011). The cost of BH4 is a concern. At 33-40 cents (US) per gram and the preferred dose of $20 \mathrm{mg} / \mathrm{Kg} /$ day, the yearly expense would range from $\$ 80,000$ to $\$ 200,000$ (child vs adult).

\subsubsection{Large neutral amino acids (LNAA)}

Large neutral amino acids (histidine, isoleucine, leucine, lysine, methionine, threonine, tryptophan, tyrosine, valine, and phenylalanine) compete for transport across the bloodbrain barrier via the L-type amino acid carrier. Hence, elevated plasma phenylalanine impairs brain uptake of the other large neutral amino acids. Since a number of these depleted amino acids are precursors of certain neurotransmitters, this may be an important factor in brain malfunction in PKU. It is hypothesized that increased blood levels of the other large neutral amino acids might lower the phenylalanine influx and, at the same time, increase the brain levels of these amino acids.

This hypothesis has been under consideration for many years. The early experiments were carried out in rats (Anderson \& Lawrence, 1976), where "control" pup rats were given phenylalanine and experimental pup rats were given phenylalanine plus large neutral amino acids. Both groups had similar serum levels of phenylalanine but the experimental group had lower brain levels. Further rat experiments were carried out (Vorhees \& Berry, 1989), where pregnant hyperphenylalaninemic rats were given supplements valine, isoleucine and leucine. This improved performance of their offspring in a complex maze test. Banos (Banos et al, 1978), in rat studies, illustrated the very rapid rate of brain amino acid influx in infancy which slows down in adulthood. This influx is interfered with, especially in infancy, if one or more of the serum amino acid levels are exceptionally high. Pratt (Pratt, 1982) reviewed the evidence to date and predicted that adding tyrosine or leucine, valine and isoleucine only, would be ineffective. Despite this, several studies in rats and humans claimed neurological/psychometric improvement with the administration of the branch chain amino acids - valine, leucine and isoleucine (Jordan, 1985; Vorhees, 1989). Experiments with 4 adult volunteers with PKU and 4 normal controls (Knudsen et al, 1995) revealed, in PKU, brain permeability to large neutral amino acids is reduced by about $50 \%$. Pietz (Pietz et al, 1999) measured brain phenylalanine by magnetic resonance spectroscopy during an oral phenylalanine challenge. Phenylalanine influx was "completely" blocked by large neutral amino acid supplementation as were EEG changes.

Since the early 90's adult patients with PKU in Denmark have been routinely treated with large neutral amino acid supplements in the form of PreKUnil@ (Nilab, Dk) but no controlled studies about efficacy have been carried out. Three recent clinical studies have been published to support this approach. Koch (Koch et al, 2003a) studied 6 adult subjects 
with PKU treated with large neutral amino acid supplementation. Blood phenylalanine concentrations remained unchanged but brain levels dropped. Matalon (Matalon et al, 2007) carried out an open label double-blind placebo control study and found a drop of 39\% from baseline of blood phenylalanine and postulated a block of phenylalanine adsorption through the bowel. Schindeler (Schindeler et al, 2007) conducted a prospective, double blind, crossover study on 16 subjects with classical PKU. At the end of each phase brain phenylalanine and other metabolites were measured by magnetic resonance spectroscopy (MRS) plus plasma amino acids and a detailed neuropsychological assessment. They had trouble with the MRS readings since they apparently had an older version of the equipment. A trend to lower plasma phenylalanine levels was observed as well as improvement in certain executive functions. They speculated that the supplements competed with phenylalanine at the gut level. They concluded that large neutral amino acids had some beneficial effect, especially in those with high phenylalanine levels. A new large neutral amino acid supplement PheBLOC ${ }^{\mathrm{TM}}$ (Applied Nutrition Corp, Cedar Falls, NJ) has been introduced and is undergoing clinical trials.

\subsection{Enzyme substitution therapy}

\subsubsection{Phenylalanine ammonia lyase (Peg-Pal®, Biomarin Inc)}

Phenylalanine ammonia lyase, a biological (plant) enzyme, transforms phenylalanine to harmless metabolites, transcinnamic acid and trace ammonia. .It may lower phenylalanine blood levels by $30-40 \%$ or more (Sarkissian et al, 2005). The original trials were on the Pahenu2/enu2 mouse model (Shedlovsky et al, 1993). One of the early problems was the development of immunogenicity. After several rounds of treatment the effect was reduced by clearance of the enzyme by a neutralizing immune response. Chemical modification with polyethylene glycol (PEG) has been successful in reducing this immunogenicity (Sarkissian, 2008). Reduction of blood and brain phenylalanine, reversal of hypopigmentation and continuation of good health was found after long term treatment in the PKU mice. The enzyme must be given subcutaneously, but once a week seems to be sufficient. The important advantage is that this treatment should be equally effective in all clinical phenotypes (most importantly Classical PKU). Clinical trials, Phase 1 and Phase 2, are now ongoing in eight treatment centres in the USA (Biomarin website, 2011). A reduction of $60 \%$ to $90 \%$ in phenylalanine blood levels have been observed with no adverse effect.

\subsection{Gene replacement therapy}

This approach toward long term correction of PKU has been, to the present, confined to the $\mathrm{PAH}$ enu2/enu2 PKU mouse has involved the use of a virus vector - the adeno-associated virus, which is non-pathogenic, minimally immunogenic and non-inflammatory (Thony, 2010). Liver gene therapy with this approach has had success in prolonged lowering of serum phenylalanine. Furthermore, the more accessible muscle, has been utilized along with intraperitoneal supplement with tetrahydrobiopterin, has had similar success. To date no human studies have been initiated. The death of one subject, due to an overwhelming immune reaction, when studying gene replacement in another disease, has served to temper this approach (Sibbald, 2001). 


\subsection{Liver cell repopulation}

Phenylalanine hydroxylase is mainly expressed in the liver. A report of a child with PKU, and unrelated cirrhosis, who underwent liver transplantation and was cured of his PKU (Varjo, 1993), led to this focus of research (Harding \& Gibson, 2010). Normally functioning hepatocytes can be introduced to the PKU liver and, if $10-20 \%$ of the liver activity is provided by these cells, the disease would be cured. Various potential sources of these cells include healthy donors, liver or hematopoetic stem cells or embryonic stem cells. The liver is unique in that it can completely regenerate after injury. The problem is that, if healthy hepatocytes are introduced, the native hepatocytes eventually replace the donor cells unless there is a selective growth advantage devised for the native cells. Successful treatment with this method in humans has been developed for several other diseases - notably lysosomal and peroxisomal storage diseases.

\section{Untreated PKU with normal intellectual function - the puzzle}

Some patients with Classical and Atypical/Mild PKU and normal intellectual function despite lack of treatment have been reported. The frequency of this "anomaly" is unclear. Textbooks continue to preach the mantra that "98\%" of individuals with untreated PKU are profoundly mentally retarded - "normal mentality is very rare among patients with PKU who have not received dietary treatment" (McKusick, 1998). This persistent claim was based on selection biased surveys from the 1950's to the 1970's of institutions for the retarded (Paine, 1957; Partington, 1962; Pitt, 1971). They found that 1-3\% of the institutional inmates suffered from PKU. In 1960 Eugene Knox (Knox, 1960) reviewed the available world literature on PKU and found reports of 466 untreated cases; 98.5\% had IQ's <60. He realized, however, the strong bias of ascertainment in these reports and stated that "most of the affected individuals have severe mental deficiency.... The few high grade cases appear to represent the extreme variation in this type, but the possible existence of substantial numbers of them in the general population has not been disproved". Based on these early, pre-newborn screening, surveys it was estimated that the incidence of PKU to be 1:25,000 in the USA (Jervis, 1939), 1:50,000 in the UK (Munro, 1947) and 1:40,000 in Sweden (Larson, 1954). This contrasts with the incidence of $1: 10,000$ to $1: 15,000$ revealed by newborn screening. The emergence of milder variants may explain some of this discrepancy. Underestimation because of early faulty data collection could be a factor. But there remains the possible existence of a significant number of normally functioning undiagnosed, untreated subjects with Classical and Atypical/Mild PKU, born before newborn screening. The epidemiologists and bioethicists continue to vehemently remind us that no statistically valid studies have ever been carried out on PKU newborn screening (Bodkin, 2005) or on PKU treatment (Rutherford et al, 2005).

Several prospective and retrospective studies to sort this out were reported, with inconclusive results. Levy et al (Levy et al, 1970) screened blood samples for PKU (submitted for syphilis screening) from 250,000 adults in Massachusetts and found only 3 adults with PKU - all 3 were mentally retarded ( 2 , in fact, were females who had produced 4 mentally retarded offspring). Levy concluded that "among those with PKU who have not received dietary therapy, very few are mentally normal". A later epidemiological review of this paper calculated that the "statistical power" was only 12\% (Hanley, 1994). Another prospective study (Machill et al, 1990) screened 233,663 pregnant women for PKU between 
1972 and 1989 and found 17 women with previously undiagnosed PKU. They concluded that $20 \%$ of untreated subjects with Classical PKU have normal IQ's. This is likely high as some assumptions were made that appeared, to this author, not valid. However, several other reports support the possibility that the incidence of normal IQ in untreated PKU is higher than originally estimated. Berman (Berman et al, 1969) and Koch (Koch et al, 1971) tested all of the unscreened older siblings of PKU neonates diagnosed in the early days of newborn screening and each found 15 with undiagnosed/untreated PKU; four (27\%) of Berman's and three (20\%) of Koch's patients had normal IQ's. Levy (Levy et al, 1983) and Waisbren (Waisbren et al, 1984) tested 453,118 umbilical cord blood samples for PKU between 1971 and 1981 and found 22 previously undiagnosed, untreated, women with PKU. Of these 2 had Classical PKU, 11 had Mild/Atypical PKU and 9 had MHP. The 2 with Classical PKU had IQ's of $45 \& 94$. Six of the 11 with Mild/Atypical PKU were available for testing and had a mean IQ of 97.3 (Range 78-107, SD 9.8). Six of the 9 with MHP were available for testing and had a mean IQ of 105.7 (Range 91-122. SD 11.8). Our review of published reports since 1990 on Maternal PKU (Hanley, 2008) - detailed above, suggests a significant population of undiagnosed PKU in the community.

What is behind this phenotypic heterogeneity? Proton nuclear resonance spectroscopy (MRS) may give some answers. Weglage (Weglage et al, 1998) describe four never treated adults with Classical PKU (blood levels $>1200 \mu \mathrm{mol} / \mathrm{L}$ ) - two retarded and two with normal IQ's. MRS revealed high brain phenylalanine levels in the retarded and low brain phenylalanine levels in the normal IQ individuals. Moats (Moats et al, 2000) carried out MRS studies in 21 Classical PKU patients. Four of these patients who had high IQ's despite having high phenylalanine levels and being off diet for at least 10 years, had low brain phenylalanine. In the majority of adult/adolescent patients with PKU brain phenylalanine is about $1 / 4$ to $1 / 2$ of the blood levels, but is closer to 1:1 in the neonate (Nuoffer et al, 2007). MRS was originally thought to detect brain phenylalanine only at blood levels of 1200 $\mu \mathrm{mol} / \mathrm{L}$ and above (0.0-1.5 Telsa), but new technology (7 \& 10 Telsa) can measure brain phenylalanine if blood levels are $200 \mu \mathrm{mol} / \mathrm{L}$ or higher (Leuzzi et al, 2007). This technique has proven difficult to many researchers who have been unable to confidently reproduce the results of the German and Italian scientist. Bik-Mutanowski (Bik-Mutanowski \& Pietrzyk, 2007) in Poland, for example, titles his frustrations "Brain phenylalanine measurements in patients with PKU: serious diagnostic method or just reading tea leaves?" If this technique can be further refined it will likely be a mandatory step in the investigation of all patients with hyperphenylaninemia.

All of this raises the possibility that "modifier genes" protect the brain of some patients with PKU - at least into early adulthood. The concept of modifier genes has been explored for some time. In foetal alcohol syndrome (FAS), for example, certain modifier genes protect the foetus against ethanol toxicity (Hanley et al, 2004b).

\section{Adult PKU and "Diet for Life"}

There is general agreement that PKU treatment should be lifelong (NIH, 2001) in the majority of patients with Classical \& Mild/Atypical PKU. As mentioned above, as the patients get older dietary control worsens - starting with the toddler and school child who can access forbidden foods when away from parental supervision to the rebellious adolescent and young adult. More than 250 patients with PKU per year enter adulthood in 
North America, double that in Europe. Close to $50 \%$ of adult patients with PKU have been lost to follow up (Burton et al, 2010). Various reports document between 50\% and 90\% not following phenylalanine restricted diets (Koch et al, 2002b; Beasley et al, 1993; Pietz et al, 1997) and more than $70 \%$ of those on treatment have phenylalanine levels above recommended values (Walter et al, 2002; Meli, 2002; Mundy, 2002). It appears that measured IQ does not deteriorate after age 12, even if diet therapy is absent or sub-optimal at least into early adulthood but, as documented above, neuropsychological, psychosocial, emotional, psychiatric and neurological problems arise in an unknown number. The effects in middle and older age groups are not yet clearly documented. The older brain in undertreated PKU may become more susceptible. The early patients diagnosed by newborn screening and treated from infancy are now just reaching their $40^{\prime} \mathrm{s}$ and $50^{\prime} \mathrm{s}$. It is crucial to continue contact with this cohort.

Deterioration of older adult PKU patients, even some never diagnosed or treated, with previously normal intellectual function, has been reported. Only some responded to introduction of therapy. Thompson (Thompson et al, 1990) documented 7 young adults, who had been off diet, (out of the UK cohort of 912 subjects) who developed quadriparesis, paraparesis, dystonia seizures, tremor and ataxia. Only two improved with dietary therapy. Weglage (Weglage et al, 2000) describes a 45 year old, previously undiagnosed, woman with an IQ of 95, who suddenly developed progressive neurological deterioration (spastic tetraparesis, ataxia, tremor, cognitive deterioration, disorientation, concentration problems). Her plasma phenylalanine was $882 \mu \mathrm{mol} / \mathrm{L}$. She was placed on a low phenylalanine diet with good blood levels and underwent complete recovery in 6 months. A 52 year old high functioning successful business man in Ontario, Canada (Adams, J 2010 - personal communication) began having neurological symptoms and seizures. He was drinking copious amounts of "Diet Coke", "Googled" aspartame and asked his neurologist to do his phenylalanine level - it was $4500 \mu \mathrm{mil} / \mathrm{L}$ (3500 off aspartame). Kasim (Kasim et al, 2001) reports a woman, with an IQ of 108, functioning normally 'till age 57, who developed slowly progressive spastic paraparesis and dementia. Her blood phenylalanine level was 2155 $\mu \mathrm{mol} / \mathrm{L}$. She was placed on phenylalanine restricted diet with "partial improvement". Ishmaru (Ishmaru et al, 1993) describes a normally functioning male who developed spastic paraparesis and dementia at age 32. Blood phenylalanine was $1663 \mu \mathrm{mol} / \mathrm{L}$. There was no response to dietary therapy.

There appears no doubt that most adult patients with PKU who are off diet therapy have measureable neuropsychological dysfunction (Moyie et al, 2007), which, in many cases, is reversible if metabolic control is reinstituted.

The establishment of PKU centres in adult facilities, modeled after that of Lee (Lee, 2002) in London, UK, is urgent. If not, the success of the neonatal screening and treatment programmes may be blunted by the development of neuropsychological, psychosocial, psychiatric and neurological problems in adult patients.

\section{Conclusions}

PKU is a "success story". It is the first example that genetic disease can be treated and adverse cognitive and physical disabilities prevented. This has subsequently led to successful treatment of a number of other genetic diseases. 


\section{References}

Anderson, AE \& Lawrence, A (1976). Lowering brain phenylalanine levels by giving other large neutral amino acids. Arch Neurol, Vol 33, pp 684-686.

Autti-Ramo L et al (1992). Dysmorphic features in offspring of alcoholic mothers. Arch Dis Child, Vol 67, pp 712-716.

Autti-Ramo L et al (2005). Expanding screening for rare metabolic diseases in the newborn: An analysis of costs, effect and ethical consequences for decision making in Finland. Acta Paediatrica, Vol 94, pp 1126-1134.

Banos, G et al (1978). The effect of age on the entry of some amino acids into the brain, and their incorporation into cerebral protein. Develop Med Child Neurol, Vol 20, pp 335346.

Beasley, MG et al (1993). Outcome of treatment in young adults with phenylketonuria detected by routine neonatal screening between 1964 and 1971. QJM, Vol 87, pp 155160.

Berman, JL et al (1969). Causes for high phenylalanine with normal tyrosine in newborn screening programs. Am J Dis Child, Vol 117, pp 54-65.

Bickle, $\mathrm{H}$ et al (1954). Influence of phenylalanine intake on the chemistry and behavior of a phenylketonuric child. Acta Paediatr, Vol 43, pp 64-77.

Bik-Mutanowski, M \& M Pietrzyk JJ (2007). Brain phenylalanine measurements in patients with phenylketonuria: a serious diagnostic method or just reading tea leaves? Mol Genet Metab, Vol 91, pp 298-299.

Biomarin Pharmaceutical Inc (2011). <www.BMRN.com>

Blau, N, et al. (2005). Disorders of phenylalanine and tetrahydrobiopterin metabolism. In: Physician's Guide to the LaboratoryDiagnosis of Metabolic Diseases. Blau, N, Duran M, Blaskovics M, Gibson, KM (Eds). Springer, Heidelberg, Germany 89-106.

Bodkin, JR (2005). Research for newborn screening: developing a national framework. Pediatrics, Vol 116, pp 862-871.

Bouchlariotou, S et al (2009). Undiagnosed maternal phenylketonuria: own clinical experience and literature review. J Matern Fetal Neonatal Med, Vol 22, pp 943-948.

Brumm, VL et al (2010). Psychiatric symptoms and disorders in phenylketonuria. Mol Genet Metab, Vol 99, pp S59-S63.

Burton, BK, et al (2007). The response of patients with phenylketonuria and elevated serum phenylalanine to treatment with oral sapropterin dihydrochloride (6Rtetrahydrobiopterin): a phase II, multicentre, open label screening study. J Inherit Metab Dis, Vol 30, pp 700-707.

Burton, BK et al (2010). Reaching out to the lost generation of adults with early treated phenylketonuria (PKU). Mol Genet Metab, Vol 101, pp 146-148.

Champigneulle, A et al (2009). The Kuvan® Adult Maternal Pediatric European Registry (KAMPER): a long term observational study of patients with hyperphenylalaninemia treated with Kuvan®. Abstract 195, The 11 th International Congress of Inborn Errors of Metabolism. CA, USA. 29 Aug - 2 Sept, 2009.

Clarren, SK \& Smith, DW (1978). The fetal alcohol syndrome. N Eng J Med, Vol 298, pp 10631067. 
Desviat, LR et al (1999). Genetic and phenotypic aspects of phenylalanine hydroxylase deficiency in Spain: Molecular survey by regions, Eur J Hum Genet, Vol 2, pp 386392.

Folling, A, (1934). Phenylpyruvic acid as a metabolic anomaly in connection with imbecility. Nord Med Tudskr. Vol 8, pp 1054-1059.

Gentile JK et al (2010). Psychosocial aspects of PKU: Hidden disabilities. Mol Genet Metab, Vol 99, pp S64-S67

Ghassan, M (2011). Newborn screening program for metabolic and endocrine disease in Qatar (6 years outcome), J Inherit Metab Dis, Vol 34(Suppl 1), p S14.

Goldbar, J et al (2002). Selective screening of amino acid disorders in the south-west of Iran. J Inherit Metab Dis, Vol 25, pp 519-521.

Grechanina, O et al (2011). Mass and selective screening in the Ukraine, Northern-East Region. J Inherit Metab Dis, Vol 34(Suppl 1), p S13.

$\mathrm{Gu}, \mathrm{XF} \&$ Chen, RG (1999). Current status of newborn screening in China. J Med Screen, Vol 6, pp 186-7.

Guthrie, R, \& Susi, A (1963). A simple phenylalanine method for detecting phenylketonuria in a large population of newborn infants. Pediatrics, Vol 32, pp 318-343.

Guttler, F, (1980). Hyperphenlalaninemia: diagnosis and classification of the various types of phenylalanine hydroxylase deficiency in childhood. Acta Paediatr Scand. Supplement 280, pp 7-80.

Hanley, WB et al (1987). Maternal phenylketonuria (PKU) - A review. Clinical Biochem, Vol 20, pp 149-156.

Hanley, WB (1994). Prenatal testing for maternal phenylketonuria (PKU). Int Pediatr, Vol 9 (Suppl 1), pp 33-39.

Hanley, WB, et al (1996). Vitamin B12 deficiency in adolescents and young adults with phenylketonuria.Eur J Pediatr, Vol 155(Suppl1), pp S145-S147.

Hanley, WB et al (2000). "Hypotyrosinemia" in phenylketonuria. Molec Genet Metab, Vol 69, pp 286-294.

Hanley WB (2004a). Adult Phenylketonuria. Am J Med, Vol 117, pp 590-595.

Hanley, WB et al (2004b). Maternal phenylketonuria collaborative study (MPKUCS) - the "outliers". J Inherit Metab Dis, Vol 27, pp 711-723.

Hanley, WB (2008). Finding the fertile woman with phenylketonuria.EJOG, Vol 137, pp 131135.

Hanley, WB (2011). Non-PKU mild hyperphenylalaninemia - The dilemma. Mol Genet Metab (in press). Vol 104, pp 23-26.

Hard, ML (2001). Impairment of pyruvate dehydrogenase activity by acedaldehyde. Alcohol, Vol 25, pp 1-8.

Harding, CO \& Gibson, KM (2010). Therapeutic liver repopulation for phenylketonuria. J Inherit Metab Dis, Vol 32, pp 681-687.

Hennerman JB et al (2005). Long-term treatment with tetrahydrobiopterin increases phenylalanine tolerance in classical and mild PKU, Mol Genet Metab, Vol 86, pp 8690.

Ishmaru, K et al (1993). Phenylketonuria with adult-onset neurological manifestations. Rinsho Shinkeigaku, Vol 33, pp 961-965.

Jervis, GA, (1937). Phenylpyruvica ologophrenia. Arch Neurol \& Psychiatr.Vol 38, pp 944-963. 
Jervis, GA (1939). Genetics of phenylpyruvic oligophrenia (Contributions to study of influence of hereditary on mental defect). J Ment Sci, Vol 85, pp 719-762.

Jervis, GA, (1953). Phenylpyruvic oligophrenia: deficiency of phenylalanine oxidizing system. Proc Soc Exp Biol Med, Vol 82, pp 514-515.

Jervis, GA. (1954). Phenylpyruvic oligophrenia (phenylketonuria). Res Publ Assoc Res Nerv Ment Dis, Vol 33, pp 259-282.

Jiang, J, (2003). A survey of the incidence of phenylketonuria in Guangdong, China. Southeast Asian J Trop Med Public Health, Vol 34(Suppl 3), pp 185.

Jordan, MK, (1985). Preliminary support for oral administration of valine, isoleucine and leucine for phenylketonuria. Develop Med \& Child Neurol, Vol 27, pp 33-39

Kasim, S et al, (2001). Phenylketonuria presenting in adulthood as progressive spastic paraparesis with dementia. J Neurol Neurosurg Psychiatry, Vol 71, pp 795-797.

Knapkova, M \& Dluholucky, S (2011). Organization of neonatal screening in Slovakia, J Inherit Metab Dis, Vol 34(Suppl 1), p S11.

Knox, E (1960). An evaluation of the treatment of phenylketonuria with diets low in phenylalanine. Pediatrics, Vol 26, pp 1-11.

Knudsen, GM et al (1995). Blood-brain barrier transport of amino acids in healthy controls and in patients with phenylketonuria. J Inherit Metab Dis, Vol 18, pp 653-664.

Koch, $\mathrm{R}$ et al (1971). In: Phenylketonuria and some other inborn errors of metabolism. Bickle H, Hudson FP, Woolf LI, Acosta PB (Eds), GT Verlag, Stuttgart, Germany, pp 20-25.

Koch R et al (1984). Paired comparisons between early treated PKU children and their matched sibling controls on intelligence and school achievement test results at eight years of age. J Inherit Metab Dis, Vol 7, pp 86-90.

Koch,R et al (2002a). Mental illness in PKU responds to Biopterin. Mol Genet \& Metab, Vol 75, pp 284-286.

Koch, R et al (2002b). Phenylketonuria in adulthood: a collaborative study. J Inherit Metab Dis, Vol 25, pp 333-346.

Koch, $\mathrm{R}$ et al (2003a) Large neutral amino acids therapy and phenylketonuria: a promising approach to treatment. Mol Genet Metab, Vol 79, pp 110-113.

Koch, $\mathrm{R}$ et al (2003b). The maternal phenylketonuria international study: 1984-2002. Pediatrics, Vol 112, pp 1523-1529.

Kurczynski, T et al (2009). Long term observations of PKU patients treated with Kuvan®: an introduction to the PKUDOD registry; and it's subregistry PKU MOMS for pregnant or nursing PKU patients, Abstract. The American College of Medical Genetics Annual Meeting. FL, USA. March 25-29. 2009.

Kure $S$ et al, (1999). Tetrahydrobiopterin responsive phenylalanine hydroxylase deficiency. J Pediatr, Vol 135, pp 375-378.

Larson, CA (1954). An estimate of the frequency of phenylketonuria in South Sweden. Fol Heret et Pathol, Vol 4, pp 40-46.

Lee, PJ, (2002). Growing older: the adult metabolic clinic. J Inherit Metab Dis, Vol 25, pp 252260.

Lee $P$ et al (2008). Safety and efficacy of 22 weeks treatment with sapropterin dihydrochloride in patients with phenylketonuria. Am J Med Genet Part A Vol 146A, pp 2851-2859. 
Lenke RR \& Levy HL (1980). Maternal phenylketonuria and hyperphenylalaninemia. An international survey of outcome of treated and untreated pregnancies. $N$ Engl J Med, Vol 303, pp 1202-1208.

Leuzzi, V et al (2007). The pathogenesis of white matter abnormalities in phenylketonuria: a multimodal 3.0 telsa MRI and magnetic resonance spectroscopy (1H-MFS) study. J Inherit Metab Dis, Vol 30, pp 209-216.

Levy $\mathrm{H}$ et al (1970). Screening the "normal" population in Massachusetts for phenylketonuria. N Engl J Med, Vol 282, pp 455-458.

Levy, HL et al (1983). Effects of untreated maternal phenylketonuria and hyperphenylalaninemia on the fetus. $N$ Engl J Med, Vol 309, pp 1269-1274.

Levy, HL \& Ghavama, M (1996). Maternal phenylketonuria: a metabolic teratogen. Teratology, Vol 53, pp 176-184.

Levy, HL et al (2007). Efficacy of sapropterin dihydrochloride (tetrahydrobiopterin, 6R-BH4) for reduction of phenylalanine concentration in patients with phenylketonuria: a phase II randomized placebo-controlled study. Lancet. Vol 370, pp 504-510.

Loeber JG, (2007). Neonatal screening in Europe: the situation in 2004, J Inherit Metab Dis, Vol 30, pp 30-38.

Mabry CC et al (1963). Maternal phenylketonuria: a cause of mental retardation in children without metabolic defect. N Engl J Med, Vol 269, pp 1404-1408.

Machill, VG et al (1990). Zur haufigkeit der phenylketonurie mit narmaler intelligenz. Z Klin Med. Vol 45, pp 182-183.

Matalon, R, et al, (1989). Hyperphenlalaninemia due to inherited deficiencies of tetrahydrobiopterin. Adv Pediatr, Vol 36, pp 67-90.

Matalon, $\mathrm{R}$ et al (2007). Double blind placebo controlled trial of large neutral amino acids in treatment of PKU: effect on blood phenylalanine. J Inherit Metab Dis, Vol 30, pp 153158.

McKusick, VA (1998). Mendelian Inheritance in Man. A Catalogue of Human Genetics and Genetic Disorders. Baltimore. Johns Hopkins University Press (12th Edition).

Meli, C, Bianca S (2002). Dietary control of phenylketonuria. Lancet, Vol 360, pp 2075-2076.

Moats, RA et al (2000). Brain phenylalanine concentration in the management of adults with phenylketonura. J Inherit Metab Dis, Vol 23, pp 7-14.

Modan-Moses, D et al (2007), Peak bone mass in patient with phenylketonuria. J Inherit Metab Dis. Vol 30, pp 202-208.

Moseley, K et al (2010). Improvement in maladaptive behavior with BH4 supplementation.J Inherit Metab Dis, Vol 33(Suppl1), pp S116.

Moyie, JJ et al (2007). A neuropsychological profile of off-diet adults with phenylkwtonuria. J Clin Exp Neuropsychol. Vol 29, pp 436-441.

Mundy, H et al (2002). Dietary control of phenylketonuria. Lancet Vol 360, p 2076.

Munro, TA (1947). Phenylketonuria: Data on 47 British Families. Ann Eugenics, Vol 14, pp 6088.

(NIH) National Institutes of Health (USA) consensus development conference statement (2001). Phenylketonuria screening and management, October 16-18, (2000). Pediatrics, Vol 108, pp 972-982.

Ney, DM et al (2009). Nutritional management of PKU with glycomacropeptide from cheese whey. J Inherit Metab Dis, Vol 32, pp 32-39. 
Niu, D-M, et al (2010). Nationwide survey of extended newborn screening by tandem mass spectrometry in Taiwan. J Inherit Metab Dis, Vol 33 (Suppl 2), pp S295-S305.

Nuoffer, JM et al (2007). The blood-brain barrier in neonates: 1H MR spectroscopy shows low protection against high phenylalanine. J Inherit Metab Dis, Vol 30 (Suppl 1), pp 13.

Paine RS (1957). The variability in manifestations of untreated patients with PKU. Pediatrics, Vol 20, pp 290-297.

Pangacon $S$ et al (2003). Phenylketonuria detected by the neonatal screening program in Thailand. Southeast Asian J Trop Med Public Health, Vol 34 (Suppl 3), pp 179-181.

Partington MW (1962). Variations in intelligence in phenylketonuria. Can Med Assoc J, Vol 86, $p p$ 736-743.

Penrose LS. (1935). Inheritance of phenylpyruvic amentia (phenylketonuria). Lancet, Vol 2, pp 192-194.

Pietz J, et al (1997). Psychiatric disorders in adult patients with early treated phenylketonuria, Pediatrics, Vol 99, pp 345-350.

Pietz, J, et al (1999). Large neutral amino acids block phenylalanine transport into brain tissue in patients with phenylketonuria. J Clin Invest, Vol 103, pp 1169-1178.

Pitt D (1971). The natural history of untreated phenylketonuria. Med J Aust, Vol 1, pp 378383.

Pratt, OE (1982). Transport inhibition in the pathology of phenylketonuria and other inherited metabolic diseases. J Inherit Metab Dis, Vol 5(Suppl 2), pp 75-81.

Robinson, BH (1987).Variable clinical presentation in patients with defective E1 component of pyruvate dehydrogenase complex. J Pediatr, Vol 111, pp 525-533.

Robinson, $M$ et al (2000). Increased risk of vitamin B12 deficiency in patients with phenylketonuria on an unrestricted or relaxed diet. J Pediatr, Vol 138, pp 545-547.

Rutherford, P et al (2005). Protein substitute for children and adults with phenylketonuria. Cochrane Database Syst Rev, Vol 19, CD004731

Salimbaeva, DN et al (2011). The neonatal screening in the Republic of Kazakhstan. J Inherit Metab Dis, Vol 34(Suppl 1), p S12.

Sarkissian, CN et al (2005). Phenylalanine ammonia lyase, substitution therapy for phenylketonuria, where are we now? Mol Genet Metab, Vol 86(Suppl 1), pp S22-26.

Sarkissian, CN (2008). Preclinical evaluation of multiple species of PEGylated recombinant phenylalanine ammonia lyase for the treatment of phenylketonuria. Proc Natl Acad Sci USA, Vol 105, pp 20894-20899.

Schindeler, $\mathrm{S}$ et al (2007). The effects of large neutral amino acid supplements in PKU: an MRS and neuropsychological study. Mol Genet Metab, Vol 91, pp 48-54.

Scriver, C (2007), The PAH gene, phenylketonuria and a paradigm shift. Hum Mutat, Vol 28, pp 831-845.

Shedlovsky A et al (1993). Mouse models of human phenylketonuria. Genetics, Vol 134, pp1205-1210.

Sibbald, B, (2001). Death but one unintended consequence of gene therapy trial. CMAJ, Vol $164, p 1612$.

Smith, ML, et al. (2000), Neuropsychological function in mild hyperphenylalaninemia. Amer J Ment Retard, Vol 105, pp 69-80. 
Szeinberg A et al (1969) Persistent mild hyperphenylalaninemia in various ethnic groups in Israel. Amer J Dis Child. Vol 118, pp 559-564.

Tada, $\mathrm{K}$ et al (1984). Follow-up study of a nation-wide neonatal metabolic screening program in Japan. A collaborative study group of neonatal screening for inborn errors of metabolism in Japan. Eur J Pediatr, Vol 142, pp 204-207.

Thompson, AJ et al (1990). Neurological deterioration in young adults with phenylketonuria. Lancet, Vol 36, pp 602-605.

Thony, B, (2010). Long-term correction of murine phenylketonuria by viral gene transfer: liver versus muscle. J Inherit Metab Dis, Vol 33, pp 677-680.

Trefz, FK et al (2009). Efficacy of Sapropropterin Dihydrochloride in increasing the phenylalanine tolerance in children with phenylketonuira: A phase III, randomized, double-blind, placebo controlled study. J Pediatr. Vol 154, pp 700-707.

Van Spronsen, FJ (2011), Mild hyperphenylalaninemia - to treat or not to treat. J Inherit Metab Dis, Feb 24, epub ahead of print. Vol 34, pp 651-656.

Varjo, P (1993). Correction of phenylketonuria after liver transplantation in a child with cirrhosis. N Engl J Med, Vol 329, p 363.

Vorhees, CV \& Berry, HK (1989). Branched chain amino acids improve complex maze learning in rat offspring prenatally exposed to hyperphenylalaninemia: Implications for maternal PKU. Pediatric Research, Vol 25, pp 568-572.

Waisbren, SE et al. (1984). Intelligence and personality characteristics in adults with untreated atypical phenylketonuria and mild hyperphenylalaninemia. J Pediatr, Vol 105, $p p$ 955-958.

Waisbren SE et al (2007). Phenylalanine blood levels and clinical outcomes in phenylketonuria: A systemic literature review and meta-analysis. .Mol Genet Metab, Vol 92, pp 63-70.

Walter, JH et al (2002). How practical are recommendations for dietary control in phenylketonuria? Lancet, Vol 360, pp 55-57.

Weglage, J et al (1998). In vivo NMR spectroscopy in patient with phenylketonuria: clinical significance of interindividual differences in brain phenylalanine concentrations. $J$ Inherit Metab Dis, Vol 221, pp 81-82.

Weglage J, et al (2000). Neurological deterioration in adult phenylketonuria.. J Inherit Metab Dis, Vol 23, pp 83-84.

Weglage J, et al (2001), Normal clinical outcome in untreated subjects with mild hyperphenylalaninemia. Pediatr Res, Vol 49, pp 532-536.

Welch MC et al (1990). Neuropsychology of early treated phenylketonuria: specific neuropsychological defects. Child Dev, Vol 61, pp 1697-1713.

Woo, SLC et al (1983). Cloned human phenylalanine hydroxylase gene allows prenatal diagnosis and carrier detection of classical phenylketonuria. Nature, Vol 306, pp 151155.

Yi, SHL et al (2011), A cross sectional study of docosahexaenoic acid status and congnitive outcome in females of reproductive age with phenylketonuria. J Inherit Metab Dis, Vol 34, pp 455-463.

Zekanowski, C et al (1997), Molecular basis of mild hyperphenalaninemia in Poland, J Med Genet, Vol 34, pp 1035-6. 
Zhan JY et al (2009). Neonatal screening for congenital hypothyroidism and phenylketonuria in China. World J Pediatr, Vol 5, pp 136-139.

Zhao ZY et al (2005). Screening for phenylketonuria in 726,998 neonates in Zhejiang Province. Zhejiang DA Xue Xue Bao Yi Xue Ban, Vol 34, pp 185-187. 


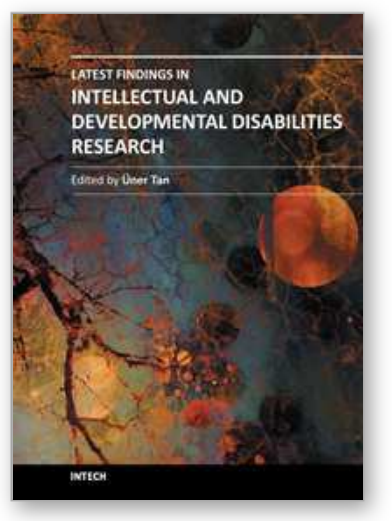

\author{
Latest Findings in Intellectual and Developmental Disabilities \\ Research \\ Edited by Prof. Uner Tan
}

ISBN 978-953-307-865-6

Hard cover, 404 pages

Publisher InTech

Published online 15, February, 2012

Published in print edition February, 2012

Intellectual and Developmental Disabilities presents reports on a wide range of areas in the field of neurological and intellectual disability, including habitual human quadrupedal locomotion with associated cognitive disabilities, Fragile $X$ syndrome, autism spectrum disorders, Down syndrome, and intellectual developmental disability among children in an African setting. Studies are presented from researchers around the world, looking at aspects as wide-ranging as the genetics behind the conditions to new and innovative therapeutic approaches.

\title{
How to reference
}

In order to correctly reference this scholarly work, feel free to copy and paste the following:

William B. Hanley (2012). Phenylketonuria (PKU) - A Success Story, Latest Findings in Intellectual and Developmental Disabilities Research, Prof. Uner Tan (Ed.), ISBN: 978-953-307-865-6, InTech, Available from: http://www.intechopen.com/books/latest-findings-in-intellectual-and-developmental-disabilitiesresearch/phenylketonuria-pku-a-success-story

\section{INTECH}

open science | open minds

\section{InTech Europe}

University Campus STeP Ri

Slavka Krautzeka 83/A

51000 Rijeka, Croatia

Phone: +385 (51) 770447

Fax: +385 (51) 686166

www.intechopen.com

\section{InTech China}

Unit 405, Office Block, Hotel Equatorial Shanghai

No.65, Yan An Road (West), Shanghai, 200040, China

中国上海市延安西路 65 号上海国际贵都大饭店办公楼 405 单元

Phone: +86-21-62489820

Fax: +86-21-62489821 
(C) 2012 The Author(s). Licensee IntechOpen. This is an open access article distributed under the terms of the Creative Commons Attribution 3.0 License, which permits unrestricted use, distribution, and reproduction in any medium, provided the original work is properly cited. 